\title{
Assessment of adverse event following immunization and its co-relates among COVID- 19 vaccine recipient in Bundelkhand region of Uttar Pradesh: A cross-sectional study
} Suneel Kumar Kaushal ${ }^{1}$, Ashok Kumar Patel ${ }^{2}$, Mukesh Yadav ${ }^{3}$, Navin Kumar ${ }^{4}$

${ }^{1}$ Professor and Vice Principal, Department of Community Medicine, Government Allopathic Medical College, Banda, Uttar Pradesh; ${ }^{2}$ Senior Resident, Department of Community Medicine, Government Allopathic Medical College, Banda, Uttar Pradesh; ${ }^{3}$ Principal, Government Allopathic Medical College, Banda, Uttar Pradesh; ${ }^{4}$ Statistician Cum Tutor, Department of Community Medicine, Government Allopathic Medical College, Banda, Uttar Pradesh

\begin{tabular}{|c|c|c|c|c|c|c|c|}
\hline Abstract & Introduction & Methodology & Results & Conclusion & References & Citation & Tables / Figures \\
\hline
\end{tabular}

\section{Corresponding Author}

Dr. Navin Kumar, Statistician Cum Tutor, Department of Community Medicine, Government Allopathic Medical College, Banda, Uttar Pradesh - 210001

E Mail ID: navin.bhu2016@gmail.com

\section{Citation}

Kaushal SK, Patel AK, Yadav M, Kumar N. Assessment of adverse event following immunization and its co-relates among COVID-19 vaccine recipient in Bundelkhand region of Uttar Pradesh: A cross-sectional study. Indian J Comm Health. 2021;33(2):379-382. https://doi.org/10.47203/IJCH.2021.v33i02.027

Source of Funding: Nil Conflict of Interest: None declared

\section{Article Cycle}

Received: 05/04/2021; Revision: 07/06/2021; Accepted: 25/06/2021; Published: 30/06/2021

This work is licensed under a Creative Commons Attribution 4.0 International License.

\section{Abstract}

Background: The COVID-19 pandemic is a global emergency. AEFIs reporting and assessment should be done with high priority as they could change the benefit-risk profile of the vaccine. Objective: To assess adverse effects after COVID-19 vaccination. Methods: This cross-sectional study conducted among 605 heath functionaries taken part from January 2021 to March 2021. Results: The most common AEFI reported was pain at injection site (51.9\%). Gender, previous COVID status and perception before vaccination were significantly associated with AEFI. Conclusion: There was no serious adverse event after vaccination. COVID vaccine has a good safety profile.

\section{Keywords}

COVID-19; AEFI; Vaccine; Uttar Pradesh; India

\section{Introduction}

Worldwide, COVID-19 has spread and nowadays the numbers of cases are again increasing. The COVID-19 pandemic is a global emergency with massive financial and human costs. Various preventive measures have been planned by the World Health Organization and ministries of health of different countries such as the social distancing, masks use, hand hygiene and use of sanitizer, and respiratory etiquettes.(1) Most of the countries have attempt lockdowns of varying lengths and intensity.(2) Our country also went into different phases of lockdown that gave time to gear up and prepare to handle a surge in the number of COVID-19 cases. It was seen that the number of cases increased after relaxation of lockdown due to poor adherence to the recommended preventive measures in India.(3) This has controlled a lot of changes in our lifestyle but vaccination must be the essential long term tool to break the chain of transmission.
The COVID-19 vaccine introduction is a unique experience for community health. There are over 120 COVID-19 vaccines in development utilizing seven very different platforms and delivery systems (killed, live attenuated, non-replicating adenovirus vector, protein subunit, replicating virus vector, mRNA and DNA).(4) Most of the developed countries nowadays are using COVID -19 vaccine namely pfizer-BioNtech, Moderna, Astrazeneca, Novavax. India has already approved two COVID-19 vaccines-Covishield and Covaxin- that are currently being administered to eligible population. WHO had granted emergency use of AstraZeneca/Oxford COVID-19 vaccine which is developed by Serum Institute of India.(5) At our centre Covishield was used.

Public health needs to be on the ground, listening to voices across diverse communities, ages, socio-economic backgrounds, religious affiliations, etc., for concerns being raised about the safety and effectiveness, and the role of vaccines in the control of COVID- 19.(6) 
An adverse event following immunization (AEFI) is "any untoward medical occurrence which follows immunization and which does not necessarily have a causal relationship with the usage of the vaccine". The adverse event may be any unfavorable or unintended sign, abnormal laboratory finding, symptom or disease. AEFIs include the background rate of all diseases postvaccination and may include excess burden of these diseases if the vaccine causes a vaccine adverse reaction.

\section{Aim \& Objective}

To find out adverse effects after COVID -19 vaccinations and to identify the associated factors with AEFI.

\section{Material \& Methods}

Study design: This was a cross-sectional study.

Study duration: The duration for this study was from January 2021 to March 2021.

Study Area: This study was conducted in a L3 tertiary care hospital, Government Allopathic medical College Banda, Uttar Pradesh.

Study Population: In this study, all participants were health care workers and medical students. Total 850 participants had registered their name for COVID-19 vaccination (COVISHIELD), after that only 650 participants had taken first dose on scheduled date and out of 650 only 605 participants had received the second dose and hence making the total study population of 605.

Data collection: Schedule method was used for data collection. The questions were asked and their responses were noted down when the participants came for the second dose. After the administration of vaccine, the recipients were under observation for 30 minutes at the session site. Initially a pilot study was conducted to pretest the questionnaire. The internal consistency of the questionnaire using Cronbach's alpha was 0.62 which indicates good level of reliability. In this study we included 20 closed ended questions. Socio-demographic profile, (age, gender, marital status, education and work profile) relevant medical history e.g. (Diabetes, Hypertension, Chronic lung disease, Thyroid disorder, Kidney and Liver disease), previous confirmed RT-PCR positive COVID-19 status, anxiety before vaccination, opinion regarding COVID-19 vaccine and self pro claimed adverse effect following immunization (AEFI) after receiving the first dose.

\section{Cause-specific definitions}

Vaccine product-related reaction: An AEFI that is caused by a vaccine due to one or more of the inherent properties of the vaccine product.

Vaccine quality defect-related reaction: An AEFI that is caused or precipitated by a vaccine due to one or more quality defects of the vaccine product. It includes the administration device, as provided by the manufacturing agency.
Immunization error-related reaction: $A n$ AEFI that is caused by inappropriate handling, prescribing or administration of vaccine.

Immunization anxiety-related reaction: An AEFI arising due to anxiety about the immunization.

Coincidental event: An AEFI that is caused by something other than the vaccine product, immunization error or fear and immunization anxiety.(7)

Inclusion criteria:

1. Health care workers and medical students, who had given written consent.

2. Age group of $18-60$ years.

Sample Size: 605 people participated in this study.

Statistical Analysis: Data has been entered in MS Excel and then transferred to trial version of SPSS 20.0. The number and percentage were calculated for AEFI with time duration. The associated factors for AEFI were estimated by calculating the odds ratio (OR) with $95 \%$ confidence interval (Cls). Ethical consideration: Ethical approval was obtained from Institutional Ethics Committee.

\section{Results}

Total 605 participants were vaccinated. Majority of the participants were in the $25-35$ year of age group (46.4\%) followed by less than 25 years (37.7\%). There were multiple adverse events seen after first dose with different time span. Most of the adverse events were seen in the period of 30 minutes to 24 hours. The most common adverse events reported after immunization was pain at injection site (51.9\%), followed by malaise (34.4\%), fever with chills $(30.9 \%)$ and headache $(16.5 \%)$. Very few participants felt adverse events before 30 minutes and after 48 hours (Table 1 ).

(Table 2) depicts the multiple logistic regression models for AEFI with predictor variables. Adjusted odds ratio for < 25 age group $\{\mathrm{OR}=30.096 ; 95 \%(\mathrm{Cl} 1.150-8.339) ; \mathrm{p}$ value $=$ 0.025 is statistically significant. As regards age group 25 35 year, the OR is 1.194 times more as compared to >35 year age group, though it is not statistically significant. Gender was significantly associated with AEFI $\{O R=0.49$; $95 \% \mathrm{Cl}(0.242-0.990) ; p$ value $=0.047\}$. Also perception of participants before vaccination $\{\mathrm{OR}=2.820 ; 95 \% \mathrm{Cl}(1.11-$ 7.159); $\mathrm{p}$ value $=0.029\}$ and Previous COVID status $\{\mathrm{OR}=2.808 ; 95 \% \mathrm{Cl}(1.420-5.551) ; \mathrm{p}$ value $=0.003\}$ were found significantly associated with AEFI.

\section{Discussion}

The study was done to assess the adverse events following immunization of COVID-19 vaccine among vaccine recipient of health workers of L3 COVID hospital of Bundelkhand region, Banda, Uttar Pradesh, India. Most of the reported adverse events were mild. It was very similar to the side effects that have been reported by the manufacturer for the COVISHIELD Vaccine. $(5,8)$ The association of age group, gender, perception of 

participants before vaccination and Previous COVID status could be the major factors for the AEFI.

In this study maximum participants were in the age group of 25-35 years (46.4\%). This study also shows preponderance among males (69.6\%). AEFI was more seen in younger age group. We found that perception of participants before vaccination is significantly associated with AEFI. 62(91.2\%) anxious and fearful people felt AEFI who were working as a health worker. The probable cause may be the first time administration of this newly launched vaccine. Still at community level, the percentage of fear and anxiety is more than we expect. Anxiety may be one of the main reasons for vaccination hesitancy. At community level, especially if immunized in mass, are more prone to have anxiety resulting in fainting and uneasiness. It was also found in the previous studies.(9) The participants who have COVID positive history felt more AEFI. More than $50 \%$ of the participants felt injection site pain.(10) In this study we also found that $92.2 \%$ of the participants have good/safe opinion regarding vaccine.

\section{Conclusion}

This study has an important aspect regarding attitude and behaviour of the people towards COVID vaccine. AEFI was seen more in younger age group and female participants. Maximum participants experienced minor and selflimiting AEFI within 24 hours. There was no serious AEFI following the vaccination. COVID vaccine has a good safety profile, and we think that our findings will encourage public to come forward and receive the vaccine to break the chain of transmission of COVID -19.

\section{Recommendation}

It is needed that more research is required related to $A E F I$ of COVID vaccine at community level for all age groups so that we can generalize for the whole population.

\section{Limitation of the study}

This study was done on only health care workers and not on all age groups, hence it lacks generalizability.

\section{Relevance of the study}

AEFI was more in younger age group less than 25 years. $A$ female preponderance was seen with AEFI.

\section{Authors Contribution}

SKK: Conception and design, definition of intellectual content, literature search, manuscript preparation, editing, review and guarantor. AKP: Conception and design, definition of intellectual content, literature search, data acquisition, data analysis, statistical analysis, manuscript preparation, editing and review. MY: Conception and design, definition of intellectual content, literature search, manuscript preparation, editing and review. NK: Conception and design, definition of intellectual content, literature search, data acquisition, data analysis, statistical analysis, manuscript preparation, editing, review and guarantor.

\section{Acknowledgement}

We are extremely thankful to all doctors and supporting health care workers of Government Allopathic Medical College, Banda for participating in this study.

\section{References}

1. Coronavirus [Internet]. Who.int. 2021 [cited 30 September 2021] Available from: https://www.who.int/healthtopics/coronavirus\#tab=tab_2

2. [Internet]. Thelancet.com. 2021 [cited 30 October 2021]. Available from: https://www.thelancet.com/pdfs/journals/lancet/PIIS01406736(20)30938-7.pdf

3. Kaushal SK, Kumar N, Yadav M, Patel AK. Modelling of COVID-19 posituve cases at tertiary care hospital of Bundelkhand region of Uttar Pradesh using regression models. Int J Community Med Public Health 2021;8:1899-903.

4. Lurie N, Saville M, Hatchette, R, \& Halton J. Developing Covid-19 vaccines at pandemic speed. The New England Journal of Medicine, 2020,382(21):1969-1973.

5. https://www.seruminstitute.com/pdf/covishield fact sheet.pdf .Last assessed on 25 June 2021.

6. Ryan MJ, Giles-Vernick T, \& Graham JE.. Technologies of trust in epidemic response: openness, reflexivity and accountability during the 2014-2016 Ebola outbreak in West Africa. BMJ Global Health, 2019;4, e001272.

7. K Park. Park's Textbook of Preventive and Social Medicine, 25th ed. Jabalpur: Bhanot Publishers; 2019:122-128.

8. https://cdsco.gov.in/opencms/export/sites/CDSCO WEB/en/Fact sheetof-ChAdSerum.pdf . Last assessed on 25 June 2021.

9. Ramasamy MN, Minassian AM, Ewer KJ, Flaxman AL, Folegatti PM, Owens DR. et al. Safety and immunogenicity of ChAdOx1 nCoV-19 vaccine administered in a prime-boost regimen in young and old adults (COV002): a single-blind, randomized, controlled, phase 2/3 trial. Lancet. 2021;396(10267):1979-1993.

10. Schmid, P., Rauber, D., Betsch, C., Lidolt, G., \& Denker, M. L. (2017). Barriers of Influenza Vaccination Intention and Behavior - A Systematic Review of Influenza Vaccine Hesitancy, 2005 - 2016. PloS one, 12(1), e0170550. https://doi.org/10.1371/journal.pone.0170550.

\section{Tables}

TABLE 1 AEFI: TYPES AND DURATION AFTER 1ST DOSE ( $N=605$ )*

\begin{tabular}{|lll|lllll|}
\hline Duration & Malaise & Nausea & Fever & Fever with chills & Injection site pain & Headache & Others \\
& $\mathrm{n}(\%)$ & $\mathrm{n}(\%)$ & $\mathrm{n}(\%)$ & $\mathrm{n}(\%)$ & $\mathrm{n}(\%)$ & $\mathrm{n}(\%)$ & $\mathrm{n}(\%)$ \\
\hline < 30 min. & $4(0.7)$ & $5(0.8)$ & $5(0.8)$ & $1(0.2)$ & $15(2.5)$ & $5(0.8)$ & $0(0.0)$ \\
\hline $\mathbf{3 0}$ min-24 hrs & $208(34.4)$ & $28(4.6)$ & $169(27.9)$ & $187(30.9)$ & $314(51.9)$ & $100(16.5)$ & $40(6.6)$ \\
\hline $\mathbf{2 4}$ hrs-48 hrs & $23(3.8)$ & $2(0.3)$ & $24(4.0)$ & $18(3.0)$ & $31(5.1)$ & $0(0.0)$ & $0(0.0)$ \\
\hline > 48 hrs & $2(0.3)$ & $0(0.0)$ & $2(0.3)$ & $0(0.0)$ & $7(1.2)$ & $2(0.3)$ & $0(0.0)$ \\
\hline *Multiple responses & & & & & \\
\hline
\end{tabular}




\begin{tabular}{|c|c|c|c|c|c|}
\hline \multirow[t]{2}{*}{ Characteristics } & \multicolumn{2}{|c|}{ AEFI } & \multirow[t]{2}{*}{ Odds ratio } & \multirow[t]{2}{*}{$95 \% \mathrm{Cl}$} & \multirow[t]{2}{*}{ P value } \\
\hline & Yes & No & & & \\
\hline Age groups(in years) & $n(\%)$ & $n(\%)$ & & & \\
\hline$<25$ & 211 (92.5) & $17(7.5)$ & 3.096 & $1.150-8.339$ & 0.025 \\
\hline $25-35$ & $224(79.4)$ & $58(20.6)$ & 1.194 & $0.624-2.287$ & 0.592 \\
\hline$>35$ & $72(75.8)$ & $23(24.2)$ & Ref. & & \\
\hline \multicolumn{6}{|l|}{ Gender } \\
\hline Male & $344(81.7)$ & 77 (18.3) & 0.490 & $0.242-0.990$ & 0.047 \\
\hline Female & $163(88.6)$ & $21(11.4)$ & Ref. & & \\
\hline \multicolumn{6}{|l|}{ Marital status } \\
\hline Married & $198(77.3)$ & $58(22.7)$ & 1.000 & $0.514-1.944$ & 0.999 \\
\hline Unmarried & 309 (88.5) & 40 (11.5) & Ref. & & \\
\hline \multicolumn{6}{|l|}{ Education } \\
\hline Up to $10^{\text {th }}$ & $32(71.1)$ & 13 (28.9) & 0.491 & $0.165-1.466$ & 0.203 \\
\hline $12^{\text {th }}$ & $243(90.3)$ & $26(9.7)$ & 1.018 & $0.351-2.951$ & 0.974 \\
\hline Graduate and above & $80(75.5)$ & $26(24.5)$ & 0.601 & $0.267-1.354$ & 0.219 \\
\hline Professional & $152(82.2)$ & $33(17.8)$ & Ref. & & \\
\hline \multicolumn{6}{|l|}{ Work profile } \\
\hline Doctors & $79(81.4)$ & $18(18.6)$ & 0.411 & $0.134-1.261$ & 0.120 \\
\hline Nursing staff & $63(76.8)$ & $19(23.2)$ & 0.150 & $0.045-0.496$ & 0.002 \\
\hline Students & $211(90.1)$ & $21(9.1)$ & 0.455 & $0.130-1.594$ & 0.218 \\
\hline Paramedical staff & $31(91.2)$ & $3(8.8)$ & 0.522 & 0.159-1.719 & 0.285 \\
\hline Others & $125(78.1)$ & $35(21.9)$ & Ref. & & \\
\hline \multicolumn{6}{|l|}{ Medical history } \\
\hline Yes & $45(95.7)$ & $2(4.3)$ & 4.220 & $0.967-18.422$ & 0.055 \\
\hline No & $462(82.8)$ & $96(17.2)$ & Ref. & & \\
\hline \multicolumn{6}{|c|}{ Perception before vaccination } \\
\hline Fear/ Anxiety & $62(91.2)$ & $6(8.8)$ & 2.820 & 1.111-7.159 & 0.029 \\
\hline None & $445(82.9)$ & $92(17.1)$ & Ref. & & \\
\hline \multicolumn{6}{|c|}{ Previous COVID-19 status } \\
\hline Positive & $120(90.2)$ & $13(9.8)$ & 2.808 & $1.420-5.551$ & 0.003 \\
\hline Unknown & $387(82.0)$ & $85(18.0)$ & Ref. & & \\
\hline
\end{tabular}

